\title{
A Note on the Consumer Benefits of Information
}

Two recent articles in this Journal provide contradictory findings on the benefits of consumer information. Brenda $J$. Cude tried a variety of measures of benefit, none of which appears as systematic as Scott Maynes' distance from the efficiency frontier, but all of which suggest very large gains from better information. ${ }^{1}$

Experimental studies by Merle D. Faminow and Bruce L. Benson, on the other hand, suggest that posted prices lead to higher average prices and profits, presumably by allowing signalling among sellers and reducing their uncertainty. ${ }^{2}$

I suggest that both findings are misleading if not incorrect. The experiments were in a duopoly framework where implicit collusion is relatively easy to induce and in a product area where margins are small anyway. Perhaps hidden-price-discounting sometimes persists more than advertised bargains, but experiments with a greater number of sellers would be more persuasive.

None of the Cude estimates of the benefits from best buys is so neatly quantitative as adding the departures from a Maynes efficiency frontier, since that might be thought of as the aggregate benefit. My problem is identifying from whence these benefits are to come. The average profit level in retailing is far below any of these estimates. Are there other monopoly rents that can be captured? Surely not in the rented space of the retailers, since other kinds of businesses compete for that space. Can one describe a process by which a new equilibrium is established with lower consumer prices? Does one drive out half the retailers and double the volume of the

James N. Morgan is a Research Scientist and Professor of Economics at the Survey Research Center of the Institute for Social Research, University of Michigan, Ann Asbor, Michigan.

The Journal of Consumer Affairs, Vol. 22, No. 1, 1988 0022-0078/88/0001-171 \$1.50/0

(C) 1988 by The American Council on Consumer Interests

1 "Estimating the Returns to Informed Decision-Making," Journal of Consumer Affairs 21 (Summer, 1987): 86-95.

${ }^{2}$ On the Implications of Reporting Retail Food Prices over Extended Periods," Journal of Consumer Affairs 21 (Summer, 1987): 40-69. 
rest with no increase in sales staff, since people need not shop so much? Can one estimate and include the savings to consumers who now do not need to shop around? Would a similar process eliminate some of the manufacturers, and lower the average costs and/or the profits of the rest? Would vast reductions in advertising also allow reductions in prices? If all these are true, the quantification of consumer benefits becomes far more difficult as it becomes more realistic. My own guess would be that the introduction of more information and/or better shopping by consumers would raise the best-buy prices, shifting the efficiency frontier, since the extra funds from uninformed buyers at non-sale periods would no longer subsidize the bargains to the smart shoppers.

One is reminded of the use of retail-wholesale spreads in food prices as an indicator of exploitation of farmers and/or of consumers. One must ask from whence the potential gains are to come, and what the dynamic process would look like. If monopoly gains have been capitalized into space rents, stock prices, and even high wages in retailing, the process of eliminating them is likely to be costly and distressing and sometimes to have unfortunate distributional (equity) implications. If, as I suspect, the gains to formerly careless shoppers are largely at the expense of formerly careful shoppers, would we applaud this? If the "careless" shoppers were poorer, harder-working (less time to shop), less educated, and more desperate, then some benefits to them, even at the expense of the more fortunate, might be considered compassionate if not just. If we eliminate a lot of jobs in retailing, what do we assume about alternatives for those workers in an area where unskilled or semi-skilled jobs are scarce anyway? We might applaud reductions in advertising expenses, in spite of some losses in subsidized television entertainment.

My apologies for complicating matters, but we need to avoid the impression that consumer economists are, in the expressive language of Kenneth Boulding, "doing good badly." 